\title{
Engaging in Engaged B2B Scholarship Relevance Squared
}

\author{
Ritter, Thomas
}

Document Version

Accepted author manuscript

Published in:

Journal of Business and Industrial Marketing

DOI:

10.1108/JBIM-11-2018-0335

Publication date:

2020

License

Unspecified

Citation for published version (APA):

Ritter, T. (2020). Engaging in Engaged B2B Scholarship: Relevance Squared. Journal of Business and Industrial Marketing, 35(4), 615-618. https://doi.org/10.1108/JBIM-11-2018-0335

Link to publication in CBS Research Portal

\section{General rights}

Copyright and moral rights for the publications made accessible in the public portal are retained by the authors and/or other copyright owners and it is a condition of accessing publications that users recognise and abide by the legal requirements associated with these rights.

Take down policy

If you believe that this document breaches copyright please contact us (research.lib@cbs.dk) providing details, and we will remove access to the work immediately and investigate your claim. 


\section{Engaging in Engaged B2B Scholarship: Relevance Squared Thomas Ritter}

Journal article (Accepted manuscript*)

\section{Please cite this article as:}

Ritter, T. (२०२०). Engaging in Engaged B२B Scholarship: Relevance Squared. Journal of Business and Industrial Marketing, 35(4), 615-618. https://doi.org/10.1108/JB|M-11-2018-0335

DOI: https://doi.org/10.1108/JBIMI-11-2018-0335

This article is [? Emerald Group Publishing and permission has been granted for this version to appear here: https://research.cbs.dk/en/publications/engaging-in-engaged-b2b-scholarship-relevance-squared

Emerald does not grant permission for this article to be further copied/distributed or hosted elsewhere without the express permission from Emerald Group Publishing Limited.

* This version of the article has been accepted for publication and undergone full peer review but has not been through the copyediting, typesetting, pagination and proofreading process, which may lead to differences between this version and the publisher's final version AKA Version of Record. 
Engaging in Engaged B2B Scholarship: Relevance Squared

\section{Thomas Ritter}

Department of Strategy and Innovation

Copenhagen Business School

Kilevej 14A, DK-2000 Frederiksberg

Denmark

Tel: +453815 2121

ritter@cbs.dk

Submission to the Special Section

Journal of Business and Industrial Marketing 


\section{Engaging in Engaged B2B Scholarship: Relevance Squared}

Researchers are often asked to point out promising research avenues and to examine how pitfalls in realizing promising research opportunities can be avoided. Over the years, I have learned to appreciate Van de Ven's (2007) ideas on engaged scholarship as a structuring device for discussing opportunities and drawbacks in research with colleagues and $\mathrm{PhD}$ students alike. I therefore structure this invited comment on the future of business-to-business research around Van de Ven's framework (see also Van de Ven and Johnson, 2006; for a critique of the approach, see McKelvey, 2006; related ideas on engaged scholarship can also be found in, e.g., Boyer, 1990, and Pettigrew, 2001).

This comment is structured as follows. First, I introduce the Van de Ven framework, after which I highlight several pitfalls that I, unfortunately, often encounter in seminars, at conferences, and in my own projects. Thereafter, I discuss several promising and important areas for further research.

\section{Engaged scholarship}

Engaged scholarship is defined "as a collaborative form of inquiry in which academics and practitioners leverage their different perspectives and competencies to coproduce knowledge about a complex problem or phenomenon that exists under conditions of uncertainty found in the world" (Van de Ven and Johnston, 2006, p. 803). I find this concept particularly suitable for research in business-to-business marketing because of the unique characteristics of the research environment. First, most business-to-business marketing research depends on practitioneracademic interaction. Managers in business-to-business markets need to participate in our studies, as we cannot substitute their expertise by using first-year students in a laboratory 
experiment. Similarly, details on many of the organizations and topics in which business-tobusiness marketing researchers are interested are not publicly available. Therefore, data collection requires direct interactions between practitioners and academics. Second, most business-to-business research projects address complex problems in which many, often idiosyncratic, elements matter and, as such, need to be considered. Therewith, "the real word" and research are interdependent in business-to-business studies. Third, given the need for interactions and collaboration to capture complexity, business-to-business research often involves a co-production or co-creation process between practitioners and academics.

Van de Ven (2007) distinguishes among four central domains of engaged scholarship ${ }^{1}$ (Figure 1): reality, theory, model, and solution. Reality is the space of managerial action-people exchange and transform resources, and they decide, respond, and act. Theory refers to a system of assumptions, definitions, and logics combined into a body of knowledge. A model takes its departure in theory but is more detailed and specific on a particular aspect. Typically, a model covers only a limited area of a theory by "modelling" a few relationships between constructs. A solution is an empirical result that proves or disproves a model. As such, a solution also contributes to the underlying theory.

**** Insert Figure 1 about here $* * * *$

These four domains in the engaged-scholarship diamond are connected by four activities: problem formulation, theory building, research design, and problem solving. Problem formulation "consists of situating, grounding, and diagnosing a research problem or issue in reality. ... the formulation of a research problem involves a complex sensemaking process of

\footnotetext{
${ }^{1}$ This short presentation of constructs is not intended to function as discussion or review of these constructs. Please see Van der Ven (2007) for an in-depth discussion and additional readings.
} 
applying various conceptual templates or theories to determine what to look for in the real world and how to unscramble empirical materials into a recognizable and meaningful research problem" (Van de Ven, 2007, p. 17). This connection is key: the interplay between reality and theory leads to a problem for which theory either has no answer or offers a different answer than reality seems to support. This interplay ensures relevance for practice and for science, as it demands investigation of a problem that occurs in managerial practice that cannot be answered using existing theory.

Theory building "involves the creation, elaboration, and justification of a body of knowledge that is relevant to the research problem. A theory is the mental image or conceptual framework that is brought to bear on the research problem" (Van de Ven, 2007, p. 19). As a dialogue between theory and model, theory building demands inner-science relevance: Which parts and aspects of a theory should be considered in a (limited) model that is part of that theory? How "true to the theory" is the model?

Research design involves "developing specific hypotheses and empirical observation procedures (based on the theoretical model) that predict what data should be obtained if the model provides a good fit to the real world. A theory is typically not open to direct inspection, while a model makes operational some specific predictions of a theory, which can be subjected to empirical inspection" (Van de Ven, 2007, p. 21). In some sense, research design is the backtranslation of problem formulation: while problem formulation brings a practice into science, research design brings a theoretical model into a realistic solution. Again, relevance is important: Are applied methods and collected data justified in relation to the model and the underlying theory? Are all procedures followed in a rigorous way? 
Problem solving "focuses on linking the research findings back to the problem observed in the practitioner and the scientific communities" (Van de Ven, 2007, p. 24). Not surprisingly, we can connect this step to relevance as well: Is the identified solution still relevant? Is the solution a suitable, well-documented answer to the original problem?

The central argument of the engaged-scholarship model is that a focus on all four domains simultaneously ensures better scientific research and better practice. In this regard, I can offer a humble example from my own work. Together with our colleagues, Achim Walter and I worked for many years on value in business relationships. In practice, managers struggled to express the contributions a given business relationship makes to an organization, and there was no theory or model to capture relationship value. Based on the (emerging) value literature and relationship-management literature, we developed a model (later called "relationship value estimation”, Ritter \& Walter, 2012) and empirically tested the ideas in different settings before finally arriving at normative suggestions that we still teach to executives today. This full cycle of engaged scholarship might be one reason that our ideas have both considerable citations in the scientific community ${ }^{2}$ and an impact in practice (e.g., the ideas are mentioned in a businessto-business marketing textbook, Brennan, Canning and McDowell, 2017).

Business-to-business research should embrace engaged scholarship to ensure its relevance for both science and practice. We need to "square" relevance in business-to-business marketing research along all four activities. For this purpose, organizations like ISBM (the Institute for the Study of Business Markets), CBIM (the Center of Business and Industrial Marketing), and MSI (the Marketing Science Institute) play important roles as bridges and ambassadors for simultaneous relevance in both camps, research and practice. Despite its importance, engaged

\footnotetext{
${ }^{2}$ Our first publication on relationship value currently has 1,153 citations on Google Scholar (Walter, Ritter \& Gemünden, 2001). Another publication has 658 citations (Walter, Müller, Helfert \& Ritter, 2003).
} 
scholarship is not always right and it is not the only way to conduct research (for critiques of engaged scholarship, see MacKelvey, 2006). However, it is a great model for starting and structuring discussions.

\section{Pitfalls in business-to-business marketing research}

Let us now revisit the four activities in the engaged-scholarship diamond and examine potential pitfalls. While the following list is neither unique nor exhaustive, it is representative of pitfalls I regularly encounter and may fall into myself.

Problem formulation: Sometimes, problems are examined that have never occurred in reality and never will. These days, such a situation is often related, but not limited, to theoretically complicated three-way interaction, moderation, and mediation effects. There are simply no real cases and, as such, no reality corresponding to the theory or the model. Such a problem formulation is essentially an argument for an argument, but without having an argument. Ten minutes into a presentation of research based on such a problem formulation, the presenter may face the ultimate request by a member of the audience - to present a real-life example of the relationship developed in the paper.

Another pitfall is engaging in overly precise descriptions of reality while forgetting to formulate a problem. This pitfall often arises in "applied programs" where the study of a certain subject is mandated by a financing body. Researchers in such situations may present a picture of reality as a case study but no one knows why that case is interesting. In other words, there is no problem to be solved. Thus, the ultimate question here is a classical one: What is the theoretical contribution? 
Theory building: Given length restrictions and depth requirements, modern publication guidelines may result in singularity in models, thereby taking complexity away from the formulated problem. But business-to-business markets are complex. Thus, we may end up with suboptimal theories because we rule out plausible explanations in order to purify the arguments and ease the argumentation. This ultimately leads to a disconnect between a (well-formulated) problem and a suitable model. The ultimate question in this regard is: Is the effect you are modelling better explained by another theory?

Research design: Adoption of an inappropriate research design is one of the biggest and, in terms of resources, most costly mistakes. There are no limits to the disappointment when a researcher realizes that the collected dataset lacks vital information, that an in-depth case study's documentation does not adequately report all necessary details, or that the applied methods were inappropriately implemented, thereby invalidating the results. There are precise demands in terms of data accuracy, item independency, database size, number of studies needed to support the argument, and so forth. All of these demands are positive, as they improve the quality of science. The downside is that some studies apparently start by collecting an impressive dataset and only later consider which theory could be relevant, leading to a disconnect between what is theoretically argued and what the research design actually supports. Challenging questions in this regard include: How can you connect your items to the construct you argue they measure? Does your method treat endogeneity correctly?

Problem solving: Another pitfall is the classic "jumping to solutions". Some empirical work is apparently designed solely to present a specific solution to a problem: How did a firm manage to solve a specific problem. While such descriptions may be an interesting reading, where are the theory and the model? What are alternative and unobserved explanations of the effects? 
While starting with reality is not problematic (as previously discussed), starting with a solution is. It becomes a problem if reality is mistaken as theory. The ultimate question here is: How can you conclude that your results are supported by theory?

\section{Avenues for research}

The excitement of researching business-to-business market management lies in the number of solutions that we need to find; the richness of theories and methods that we can explore, apply, and develop; and the ever-changing reality we face in business markets. In other words, all building blocks of the engaged-scholarship diamond offer ample opportunities to start a journey of discovery - remembering that one needs to address each quadrant in the diamond to engage in engaged scholarship. In the following, I highlight a few examples of potentially valuable research avenues. This is not a complete list nor is it prioritized.

Reality: The reality, or realities, of business-to-business markets are constantly changing. Currently, we are witnessing servitization and digitalization as major trends in business-tobusiness markets. The speed of the transition from product-based to service-based business models (and vice versa) and the speed of digital transformations are extremely fast, and research in these areas often seems to be catching up with current developments rather than staying at the forefront. These topics have already triggered a considerable amount of research, but they are far from fully explored. As such, they will remain high on executives' lists of important areas - and given this importance in reality and the constant search for solutions, these topics should also be important for research.

Another key issue is the impact of political dynamics on business-to-business markets. Current developments stress-test our understanding of markets. In particular, notions and political 
actions focused on reducing globalization and global integration offer interesting areas for research.

As a third issue related to reality, the discussion and experience of disruption continue to garner attention. Many, if not all, executives debate disruption, which they also refer to as exponential growth, and search for answers to their questions. In this debate, the lack of conceptual clarity ("What is disruption?") and the lack of a relevance test ("Is exponential growth relevant for my industry?") stand in the way of making sense of reality as it unfolds.

Theory: While research into business-to-business markets has benefitted from adopting theories from areas such as sociology, complexity (NK models) and biology (e.g., Wilkinson, Young and Freytag, 2005), there are ample opportunities for exploring the applicability of a wide range of theories. For example, the business-to-business field has not explored dominant management theories, such as dynamic capabilities and micro foundations (Felin, Foss, Heimeriks, and Madsen, 2012), to their full potential. Relatedly, marketing research and strategy research have only shown initial cross-overs (e.g., the discussion of market orientation had an impact in both areas; see Jaworski and Kohli, 1993). This has created a situation of coevolution of the marketing and demand-side perspectives (Priem, Li and Carr, 2012) in strategy without too much interaction.

Model: We have seen significant advances in modelling: constructs are much better defined, hypotheses are better argued, and the domain of applicability of a given effect is much better understood. As such, the quality of models in business-to-business market research has improved. This is necessary for ensuring rigor in research. However, new methods are available for business-to-business market research that warrant investigation. Examples include 
laboratory research and the application of big data. In recent years, consumer marketing has extensively moved toward using experiments to test theories. Such approaches offer the potential for new or refined insights, as experiments can be designed to test much more finegrained models. The challenge in business-to-business market research is that the test subjects cannot be undergraduate students - they must be business executives. This challenge might be solved through the use of highly relevant research questions to motive executives to participate as well as highly mobile and flexible lab equipment.

Moreover, digitization offers a lot of data on business-to-business market practices that we did not have before and we have not exploited thus far. For example, many executive activities are now digitally captured, including meetings, movements, and performance. As such, researchers do not have to rely on self-reporting but can use secondary data, which is less biased.

Solution: As reality is changing in business-to-business markets, so are the solutions available for affecting that reality. I discuss two topics in this regard: the options available for solving an issue and the methods of communication. There are plenty of new technologies available for building solutions to managerial problems. Again, the digitization of business and society offers new ways of implementing solutions so that a new reality forms. For example, monitoring customer behavior to ensure better service provision and appropriate pricing is possible today. This opens interesting avenues for research that consider new forms of supplier-customer interactions and business solutions.

With regard to the communication of research results, researchers have plenty of opportunities. In addition to classical forms of research dissemination, such as articles in the business press, talks at industry gatherings, and booklets, research can be disseminated via video, interactive 
web solutions, and games, to name a few. These types of dissemination are, in themselves, a field of study: How can we best get a message across to ensure an impact on practice? 


\section{References}

Boyer, E. L. (1990). Scholarship reconsidered: priorities of the professorate. Princeton, NJ: Carnegie Foundation.

Brennan, R., Cunning, L., \& McDowell, R. (2017). Business-to-business marketing (4th ed.). London: Sage Publications.

Felin, T., Foss, N. J., Heimeriks, K. H., \& Madsen, T. L. (2012). Microfoundations of routines and capabilities: individuals, processes, and structure. Journal of Management Studies, 49(8), 1351-1374.

Jaworski, B. J., \& Kohli, A. K. (1993). Market orientation: antecedents and consequences. Journal of Marketing, 57(3), 53-70.

McKelvey, B. (2006). Van de Ven and Johnsons "engaged scholarship": nice try, but. Academy of Management Review, 31(4), 822-829.

Pettigrew, A. M. (2001). Management research after modernism. British Journal of Management, 12, S61-S70.

Priem, R. L., Li, S., \& Carr, J. C. (2012). Insights and new directions from demand-side approaches to technology, innovation, entrepreneurship, and strategic management research. Journal of Management, 38(1), 346-374. https://doi.org/10.1177/0149206311429614

Ritter, T., \& Walter, A. (2012). More is not always better: the impact of relationship functions on customer-perceived relationship value. Industrial Marketing Management, 41(1), 136-144. https://doi.org/10.1016/j.indmarman.2011.11.020

Van de Ven, A. H. (2007). Engaged scholarschip: a guide ofr organizational and social research. Oxford: Oxford University Press.

Van de Ven, A. H., \& Johnson, P. E. (2006). Knowledge for theory and practice. Academy of Management Reviewview, 31(4), 802-821.

Walter, A., Mu, T. A., Helfert, G., \& Ritter, T. (2003). Functions of industrial supplier relationships and their impact on relationship quality. Industrial Marketing Management, 32(1), 159-169.

Walter, A., Ritter, T., \& Gemünden, H. G. (2001). Value creation in buyer-seller relationships. Industrial Marketing Management, 30(4), 365-377.

Wilkinson, I., Young, L., \& Freytag, P. V. (2005). Business mating: who chooses and who gets chosen? Industrial Marketing Management, 34(7), 669-680. 


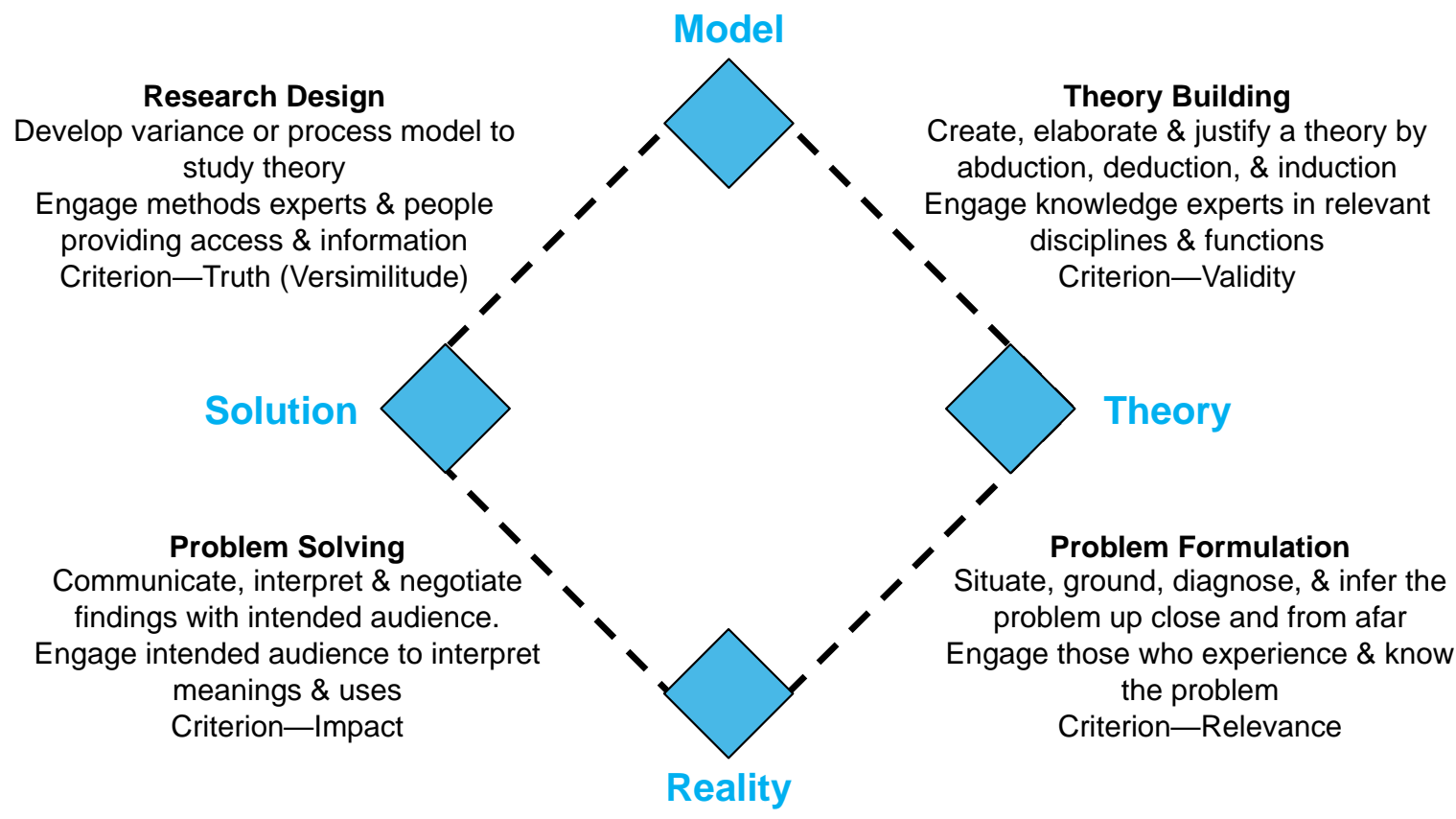

Figure 1: Engaged-scholarship diamond model by Van de Ven (2007, p. 10) 